\title{
Readiness for Online Learning: \\ Learners' Comfort and Self-Directed Learning Ability
}

Vy Luu Thi Mai ${ }^{1 *}$

${ }^{1}$ Ho Chi Minh City University of Economics and Finance, Vietnam

*Corresponding author's email: vyltm@uef.edu.vn

https://orcid.org/0000-0003-0231-3863

do) https://doi.org/10.54855/ijte.222113

Received: 26/11/2021 Revision: 20/12/2021 Accepted: 15/01/2022 Online: 18/01/2022

ABSTRACT

The need for transforming conventional learning to online learning among educational institutions during the coronavirus outbreak is inevitable. However, this shift comes with many challenges for both learners and teachers as they have become habitual to the traditional method for such a long time. Research has shown that students' online learning readiness (OLR) is considered a valid predictor for accomplishing online coursework successfully. Therefore, this paper presents the findings of an examination on students' readiness for online learning in a private university in the South of Vietnam. A selfevaluation OLR survey with a 4-Likert scale was distributed to 304 undergraduate students. The questionnaire highlighted two dimensions: learners' comfort with e-learning and self-directed online learning. Responses were coded and analyzed by SPSS to calculate the descriptive statistics and reliability. Data analysis revealed that these students' readiness level was only at a moderate

Keywords: Online learning, readiness, comfort, self-directed learning level, which may account for their resistance to embrace virtual learning as an alternative for a classroom-based environment amidst the disease crisis. Considering the results of the study, some pedagogical implications are also discussed.

\section{Introduction}

During the severe explosion of COVID-19, online learning has become the only alternative that academic institutions must adopt as a mode of teaching and learning with no exception in the Vietnamese context (e.g, Le, 2021). Indeed, online learning has served as a panacea at the time of this outbreak (Dhawan, 2020). However, shifting classroom-based learning to virtual learning confronts many challenges and requires a high level of readiness. This is partly because of the resistance to change of both learners and teachers who have become habitual to the traditional method of teaching and learning. Moreover, becoming virtual learners also means that learners have to adopt a new mindset for learning which is quite divergent from the one in traditional teaching and learning environments (Muliyah et al., 2020). To illustrate, there is a huge demand for independence and self-control for a real accomplishment. Learners may be 
unsure about how to navigate in environments with lessened control due to their familiarity with the manipulation of a teacher.

Meanwhile, one of the underlying factors which contribute to the success as well as a failure of the online course is online learning readiness (OLR) (Rivera, 2018). At a personal level, learners can self-evaluate their preparedness as a self-reflection to get ready for the transformation. At an organizational level, collecting applicable data on students' preparedness for online learning can enable the institutions to deliver and manage courses in a way that learners can function effectively. They even can assist students in developing effective strategies to achieve better outcomes or increase their overall satisfaction with the experience (Rivera, 2018). Numerous researchers have attempted to develop survey-based instruments for self-assessing online learning readiness (Burrows \& Stepanczuk, 2013; Dray et al., 2011; Hung et al., 2010; McVay, 2004; Naji et al., 2020; Pillay et al., 2006; Smith et al., 2003). These studies have shown that learners' readiness is a crucial factor in online environments. Especially, it is considered as a multifaceted concept, and its indicators may vary, depending on the contexts. For instance, in Hung et al.'s study (2010), OLR consists of 5 dimensions: self-directed learning, motivation for learning, internet self-efficacy, online communication self-efficacy, and learner control, while Pillay et al.'s (2006) identified four constructs: technical skills, learner self-efficacy, learning preference and learner attitude. Recent investigations have also been conducted into the relationship between OLR and students' perception, online engagement, and achievement (Prihastiwi et al., 2021; Warden et al., 2020; Wei \& Chou, 2020). These outcomes reveal that OLR exerts a certain observable effect on students' performance as well engagement in online learning. Regarding online learning in the Vietnamese context, only a few studies were carried out to assess students' satisfaction (Dinh \& Nguyen, 2020, Tran \& Nguyen, 2022) and to determine the factors that influence students' intentions of studying online (Maheshwari, 2021). How ready the students are for online learning is still under-researched.

Taken together, given the vital role of OLR in the online learning environment, this paper aims to examine the level of OLR of Vietnamese EFL learners in a private university in Ho Chi Minh city when they are required to take online learning courses as a replacement for traditional learning due to the ongoing pandemic. As their individual experiences shape learners' OLR under the influence of specific contexts and processes (Holt et al., 2007), it is essential to conduct an investigation into learners' OLR in the Vietnamese context where online learning is still in its infancy. The originality of this study is that it, for the first time, explores learners' preparedness for online learning in the Vietnamese context with a focus on learners' comfort and their self-directed ability in the online learning space as predictors of OLR.

\section{Literature review}

\section{Online learning readiness $(O L R)$}

According to Holt et al. (2007), readiness is not a trait but a state because it is conceptualized as an individual's attitude toward a particular change. This attitude is shaped and evolves based 
on individual experience with the organization and its cultures under the influence of the content, the process, the context, and the individuals. Therefore, at a certain point of a transformation, the level of readiness is different. During the outbreak of coronavirus disease, the fact that face-to-face learning replaces online learning is inevitable. In this regard, learners' OLR has been considered as a contributing factor to their performances as well as their satisfaction in online learning. The earliest attempt to identify the components of OLR is by Warner et al. (1988), who suggested that OLR includes students' preference for online mode, students' competence as well as confidence in utilizing digital communications for learning, and their capacity to participate in autonomous environments actively.

Later, many studies have been done to identify the indicators of OLR. The first two variables developed by McVay (2000) are comfort with e-learning and self-management or self-directed learning ability in e-learning. These constructs were then validated by Smith et al. (2003) as an applicable research instrument in assessing readiness for online learning. After that, the notion of OLR was expanded to adapt to the requirements of the advances as well as the prevalence of technology. For instance, Hung et al. (2010) implemented a survey among 1051 students and discovered five dimensions of ORL: self-directed learning, motivation for learning, internet self-efficacy, online communication self-efficacy, and learner control. They concluded that two factors, learner control and self-directed learning, need more attention. Recently, Wei and Chou (2020) and Prihastiwi et al. (2021) utilized the Hung et al. (2010) survey to determine the effect of e-learning on learners' perception and learner's engagement, respectively. Their results indicate that the more positive students' perception is, the readier they are for online learning. Besides, self-directed learning is found to be the most influential component of e-learning readiness to engage learners, then internet self-efficacy, and online communication selfefficacy.

In another investigation with 92 students by Burrows and Stepanczuk (2013), a tool for estimating OLR was also proposed. In their study, two variables were identified: demographic and non-demographic. In the latter category, five dimensions are identified for measuring learners' OLR: learner autonomy, computer self-efficacy, attitude towards online learning, motivation, and English language self-efficacy. In the same vein, based on a review of instruments and survey of OLR, Martin et al. (2020) created a questionnaire containing four common constructs: online student characteristics, time control, technical and communication competencies. Then, it was administered to 177 students. The results reveal that students rated communication competencies the least important among the four. Moreover, compared to time management and communication, they showed more confidence in online student attributes and capacity. Furthermore, Warden et al. (2020) investigated how the difference in readiness for technology relates to learners' ability to be self-efficacious, engage, and achieve in an online class. In an online business negotiation class with 102 participants, the findings show that regardless of their level of technology readiness, students felt self-confident in fulfilling technological tasks. In contrast, students with less comfort with technology were less selfefficacious in social interactions. Unlike the above researchers, in Naji et al.'s work (2020), data 
were gathered not only from a survey of 140 participants but also from 68 written reflections and eight semi-structured interviews. The results of the study indicate that early preparedness and motivation for online learning, online self-efficacy percepts, self-directed learning online, and support are not fully aware, although they have a considerable bearing on learners' readiness for changes in urgent situations.

In brief, the review of these studies demonstrates that OLR is a complex concept, and the level of readiness may change depending on the context and the learners' characteristics. Besides, OLR involves a diversity of variables or skills for learners to achieve success in online courses. Having said that, the current study seeks to explore how ready the students are regarding two readiness dimensions proposed by McVay (2004). They are learners' comfort with e-learning and their self-directed learning ability in online settings. The underlying rationale for this choice is that the study aims to get an overall picture depicting the factors that come from inside the learners rather than the external factors. Besides, since learners have no prior experiences in online learning mode but tend to show a strong resistance, it is essential to highlight their comfort with as well as their self-directed learning ability in online learning spaces.

\section{Comfort with e-learning}

E-learning or online learning is a mode of learning in which teaching contents are provided online, and teaching modules are developed to strengthen learning and interactivity synchronously or asynchronously (Singh \& Thurman, 2019). In this sense, comfort in online learning is described as learners' willingness to interact with peers and teachers via computermediated communication using emails, discussion boards, chatboxes, etc., and their confidence in accessing these resources (McVay, 2001; Smith, 2005). Virtual learning contrasts with conventional face-to-face learning in a way that it mainly relies on the electronic medium for sharing understandings, clarifying misconceptions, developing knowledge, etc. Therefore, once learners are willing to engage collaboratively with others in an electronic manner, this can allow them to achieve successful outcomes in their academic performances. The findings of a study by Warden et al. (2020) indicate that learners who tend to feel uncomfortable with technology are quite less self-efficacious in social interactions, resulting in low participation in online learning settings. Even though learners may use a wide range of technological tools for entertainment and personal development, they seem to be ill-literate in using digital knowledge to support their learning in some circumstances (Kennedy \& Fox, 2013).

Moreover, constructing an online environment where students find it safe, easy, and convenient can minimize the possibility of causing them vulnerabilities, removing barriers that hindered their learning and success (Futch et al., 2016). Later, the concept of comfort with e-learning is thoroughly examined divided into different constructs such as internet self-efficacy, online communication self-efficacy communication competencies (Hung et al., 2010; Martin et al., 2020 , etc.). 


\section{Self-direct online learning}

Previous studies have shown that self-directed learning (SDL) is one of the strong predictors for readiness for online learning (Hung et al., 2010, Naji et al., 2020, Widodo et al., 2020 etc.). In particular, this factor is found to make the biggest contribution to engagement in online learning (Prihastiwi et al., 2021). Basically, SDL is described as "a process in which individuals take the initiative, with or without the help of others, in diagnosing their learning needs, formulating learning goals, identifying human and material resources for learning, choosing and implementing appropriate learning strategies, and evaluating learning outcomes" (Knowles, 1975, p.18). Simply put, self-directed learners know how to decide and organize all aspects of learning to fit their personal needs. Becoming SDL not only reflects a natural human process of psychological development but also fulfills the requirements of the innovations in education that request learners to take more initiative in their learning (Knowles, 1975). These characteristics have a close connection with learners' lifelong learning tendencies (Tekkol \& Demirel, 2018). Given these features, the ability of self-directing in online learning settings cannot be overlooked when learners' OLR is evaluated.

In another sense, self-direction can be seen as the integration of self-management, selfmonitoring, and motivation (Garrison, 1997). These features are essential for online learners because the virtual environments place more responsibility for organizing learning on the individuals. On the other hand, online learning also lends itself to the cultivation of SDL. In online learning environments, learners have the conditions to improve their abilities to manage their overall learning activities and monitor their performances (Kim et al., 2014). When learners take control of their learning, they become more engaged and even develop a mindset for the long-term language learning goal (Haworth, 2016). As stated by Smith (2005), selfdirection is a prerequisite for academic success in online environments. Learners with the ability of self-direction can achieve better performances with online learning modes (Chou, 2012). This ability can enable them to behave appropriately and to become more disciplined in their own learning journey (Lasfeto \& Ulfa, 2020).

\section{Research Questions}

Are university students ready for online learning? If yes, to which extent?

\section{Methods}

\section{Pedagogical Setting \& Participants}

The study was conducted at a private university in Ho Chi Minh City. During the COVID-19 outbreak, face-to-face learning in many areas was suspended. Instead, educational institutions were encouraged to switch to online modes of delivery. However, the majority of the students were not in favor of online learning, which led to a delay for a trimester during the outbreak. When students came back to school after the first outbreak, 304 students in 8 classes were randomly chosen to take part in the study. Participants were freshmen and sophomores with 
ages ranging from 18 to 23 years old. Their majors included management, communications, marketing, and others, and they came from different regions in Vietnam. Despite their disparity in backgrounds, they all shared a commonality that was, they have never taken any English course in a full online mode.

\section{Design of the Study}

As the nature of the current research was descriptive and exploratory, it adopted a questionnaire as a research instrument. It was a survey of McVay (2004), a revised version from McVay in 2000, validated by Smith et al. (2003) and Smith (2005). The survey was proved to be reliable and valid for measuring two factors: comfort with e-learning and self-management of online learning or self-directed online learning. As argued by Smith (2005), this questionnaire is an applicable and practical tool for research and practice regarding readiness for online learning with an emphasis on these two factors above. The survey consists of 14 items with a 4-point Likert scale ( $1=$ Rarely, $2=$ Sometimes, $3=$ Most of the time, $4=$ All of the time). The first six items were interpreted as comfort with e-learning, loaded highly on factor 1, and factor 2 were considered as self-directed online learning, including 8 items.

\section{Data collection \& analysis}

The questionnaire was distributed to participants during the teaching time of 8 classes chosen randomly. Students were instructed to fill out the form online by choosing the scale representing their level of agreement with 14 statements. Then, data were collected, coded, and analyzed using SPSS 14.

\section{Findings and discussion}

Table 1 illustrates the descriptive statistics of the two factors as indicators of students' readiness for online learning. It can be seen that the overall participants were relatively ready for online learning. Specifically, they had an average level of comfort with e-learning $(\mathrm{M}=2.95, \mathrm{SD}=3.62)$, and their self-directed online learning ability was fairly at an acceptable level $(\mathrm{M}=3.03$, $\mathrm{SD}=4.62$ ). These findings may account for the students' resistance to adopt online learning amidst the pandemic because the state of their readiness was more or less at a moderate level. A possible explanation is that students' level of comfort plays a significant role in alleviating their susceptibilities and removing roadblocks that may hinder their learning success (Futch et al., 2016).

Table 1. Descriptive measures of the survey factors

\begin{tabular}{ccccccc}
\hline Factor & Mean & SD & Minimum & Maximum & $\begin{array}{c}\text { N of } \\
\text { Items }\end{array}$ & $\begin{array}{c}\text { Cronbach's } \\
\text { Alpha }\end{array}$ \\
\hline Comfort with e-learning & 2.95 & 3.62 & 2.38 & 3.44 & 6 & .74 \\
Self-directed online learning & 3.03 & 4.62 & 2.73 & 3.20 & 8 & .80 \\
\hline
\end{tabular}

Within each of the subscales, the means and standard deviations by item are reported in Table

2. Regarding items evaluating learners' comfort with online learning, the highest value 
$(M=3.44)$ was rated for the first statement about their ability to get access to the Internet for learning, whereas the lowest value was item $4(\mathrm{M}=2.38)$ concerning the comparison between the quality of online learning and the conventional classroom learning. These results indicate that, basically, the students can have access to the Internet when they need it for their studies. Struggle with Internet access quality may be one of the barriers to online learning (Dinh \& Nguyen, 2020), but in this case, for the majority of the participants in the current study, network access is not a major problem. Besides, it is interesting that most students undervalued the quality of online learning compared to the traditional learning model. This can be ascribed to the fact that students have been familiar with the face-to-face classroom as a result of their upbringing and pedagogical practices. Traditional classrooms have become students' habitual mode of learning, which involves more physical interactions, more social presence, and more teacher-centered preference (McVay, 2004). Therefore, to remove these barriers, students are required to first adopt a new mindset that is fully aware of the benefits of virtual learning, accompanied by the equipment of appropriate skills for online learning (Dhawan, 2020).

Table 2. Descriptive measures of the survey items

\begin{tabular}{|c|c|c|c|c|}
\hline Factor 1- Comfort with e-learning & Mean & SD & $\mathbf{N}$ & $\begin{array}{c}\text { Cronbach's } \\
\text { Alpha }\end{array}$ \\
\hline 1. I can easily access the Internet to facilitate my studies. & 3.44 & .71 & 304 & .73 \\
\hline 2. I can communicate with others online with ease. & 3.07 & .89 & 304 & .71 \\
\hline $\begin{array}{l}\text { 3. I am willing to communicate actively with my } \\
\text { classmates and instructors electronically. }\end{array}$ & 2.95 & .96 & 304 & .70 \\
\hline $\begin{array}{l}\text { 4. I feel that online learning is equal to traditional learning } \\
\text { regarding the quality. }\end{array}$ & 2.38 & 1.02 & 304 & .71 \\
\hline $\begin{array}{l}\text { 5. I feel that I can make use of my background and } \\
\text { experience in my studies for online learning. }\end{array}$ & 2.86 & .87 & 304 & .70 \\
\hline 6. I am comfortable with online written communication. & 3.01 & .98 & 304 & .71 \\
\hline Factor 2- Self-directed online learning & Mean & SD & $\mathbf{N}$ & $\begin{array}{c}\text { Cronbach's } \\
\text { Alpha }\end{array}$ \\
\hline $\begin{array}{l}\text { 7. I am willing to allocate an appropriate amount of time } \\
\text { weekly to successfully engage in study. }\end{array}$ & 3.20 & .88 & 304 & .74 \\
\hline 8. I believe that I am a self-directed learner. & 2.96 & .86 & 304 & .77 \\
\hline $\begin{array}{l}\text { 9. Reviewing prior knowledge in a course is helpful for } \\
\text { the new learning. }\end{array}$ & 3.02 & .90 & 304 & .79 \\
\hline $\begin{array}{l}\text { 10. In my studies I am self-disciplined and have no } \\
\text { difficulty in setting aside homework time. }\end{array}$ & 2.73 & .94 & 304 & .77 \\
\hline $\begin{array}{l}\text { 11. I am able to manage my study time productively and } \\
\text { simply complete assignments on time. }\end{array}$ & 3.18 & .81 & 304 & .79 \\
\hline $\begin{array}{l}\text { 12. As a student, I enjoy working by myself with a } \\
\text { minimum of support or interaction. }\end{array}$ & 2.88 & .96 & 304 & .80 \\
\hline 13. I can set goals and highly take initiative in my studies & 3.08 & .78 & 304 & .77 \\
\hline $\begin{array}{l}\text { 14. I believe no one has the responsibility for my learning } \\
\text { except myself. }\end{array}$ & 3.19 & .95 & 304 & .81 \\
\hline
\end{tabular}


The other items $(2,3,5,6)$ were rated as Most of the time with $\mathrm{M}=3.07, \mathrm{M}=2.95, \mathrm{M}=2.86$, $\mathrm{M}=3.01$, respectively. This demonstrates that students are fairly comfortable with online communication and are voluntary to communicate with classmates and instructors digitally only to some extent. These responses may reflect the findings in Kennedy and Fox's study (2013), stating that although learners are supposed to be digital natives in a sense that they can make the most of technological tools for recreational and communicative purposes on their daily basis, they tend to lack a certain of knowledge of using these resources to serve for their learning purposes.

Concerning the items evaluating learners' self-direction in online learning displayed in Table 2, no statistically significant difference was identified between the means of each statement. Most of the means were about 3.0, with the highest value at $\mathrm{M}=3.20$ for item 7 , regarding their willingness to set aside time for effective engagement in study, and the lowest value at $\mathrm{M}=2.73$ for item 10 relating to their self-discipline in completing homework. These data suggest that, on average, students rated their ability to be self-directed in online learning as somewhat at a medium level. They may be aware of the responsibility for their own learning but still have a tendency to rely on the teachers. This seems to contradict the assumption that online learners are able to be highly self-directed to master the training content and use self-regulated learning strategies to have better achievements in e-learning performances (Chu \& Tsai, 2009). If learners are not equipped with a high level of readiness, they are not confident and motivated to take charge of their learning or cannot benefit from their self-control and self-management abilities during the whole learning process (Lee et al., 2017). The respondents in the present study were not fully self-directed learners because they have been accustomed to the teachers' control and presence. Consequently, they perceived themselves as passive, less autonomous learners.

\section{Conclusions and Pedagogic Implications}

To conclude, the present study aims to examine students' readiness for online learning at a private university in Ho Chi Minh City during the coronavirus pandemic. In light of the obtained findings, it can be inferred that the student's readiness for e-learning is quite moderate. Results of a survey-based self-evaluation indicate that their comfort with online learning and selfdirected ability in online learning were both just at a medium level. These findings add to the rapidly expanding field of online learning during the pandemic by providing an alternative understanding of the significance of learners' readiness for online learning with an emphasis on learners' comfort and self-directed learning ability. Apparently, a shift to virtual platforms to catch up with the curriculum during the Covid-19 crisis may require different aspects of the reorientation from both learners and teachers. Especially understanding how ready these students are for virtual learning has some significant implications for educators and institutions.

In order to accommodate the transformation into fully virtual learning modes, a high level of preparedness is needed (Dhawan, 2020). In particular, for learners in a context where they have 
been conditioned to depend on the teachers' presence with immediate feedback and close monitoring of their progress like the participants in this study, online learning seems to be more challenging because of the restrictions of technological tools, the suspension of feedback and the incompetence of the instructor to handle resources appropriately digitally (Muthuprasad et al., 2021). Most importantly, learners at these ages are mainly influenced by their backgrounds in ways that tend to stifle their abilities to be self-directing in a particular learning situation (Brookfield, 2009). The cultural contexts may have molded their needs, values, and beliefs. Therefore, for effective implementation of online learning, orientation courses about all aspects of online learning should be offered from the outset. These courses should aim to raise learners' awareness of the merits of virtual learning and provide encouragement and reassurance for developing a new mindset in online learning. This may help learners gain a more accurate perception of virtual learning, resulting in less resistance to the transformation. Furthermore, the insights gained from this study are helpful for teachers to understand their students better and to reconsider their teaching approaches in giving instructions in online settings. As stated by McVay (2004), the role of the teachers in a world full of data and uncertainty is "not to provide information but to guide students wading through the deep waters of the information flood" (p.15). By doing that, teachers can train the students to develop and sharpen their selfdirected learning abilities. Moreover, based on the characteristics of learners, course developers should also consider designing online learning venues in which learners feel comfortable and confident to complete their assignments. Above all, a learning system should be built with conditions to develop students' self-directed learning ability. Essential strategies for selfdirection should also be accessible to learners in case they may need consultation.

Despite the significant contributions to the current related field, the study has a few weaknesses. Since the survey was administered before the implementation of online learning, it was not possible to evaluate learners' readiness regarding their technological competencies. Future work should investigate this issue to see how different these learners have changed when coping with tasks in online learning in this context. Besides, although the teachers' readiness for online learning is also a contributing factor to the success of online learning, it is beyond the scope of this study.

\section{References}

Brookfield, S. D. (2009). Self-directed learning. In R. Maclean \& D. Wilson (Eds.), International handbook of education for the changing world of work (pp. 2615-2628). Springer. https://doi.org/10.1007/978-1-4020-5281-1_79

Burrows, T., \& Stepanczuk, D. (2013). Gauge of readiness for language learning : An 800 pound GORILLa. JALT CALL Journal, 9(2), 197-217.

Chou, P. (2012). The relationship between engineering students ' self -directed learning abilities and online learning performances: A pilot study. Contemporary Issues in Education Research, 5(1), 1-6.

Chu, R. J. C., \& Tsai, C. C. (2009). Self-directed learning readiness, Internet self-efficacy and 
preferences towards constructivist Internet-based learning environments among higher-aged adults. Journal of Computer Assisted Learning, 25(5), 489-501. https://doi.org/10.1111/j.1365-2729.2009.00324.x

Dhawan, S. (2020). Online learning: A panacea in the time of COVID-19 crisis. Journal of Educational Technology Systems, 49(1), 5-22. https://doi.org/10.1177/0047239520934018

Dinh, L. P., \& Nguyen, T. T. (2020). Pandemic, social distancing, and social work education: students' satisfaction with online education in Vietnam. Social Work Education, 39(8), 1074-1083. https://doi.org/10.1080/02615479.2020.1823365

Dray, B. J., Lowenthal, P. R., Miszkiewicz, M. J., Ruiz-Primo, M. A., \& Marczynski, K. (2011). Developing an instrument to assess student readiness for online learning: A validation study. Distance Education, 32(1), 29-47. https://doi.org/10.1080/01587919.2011.565496

Futch, L. S., Denoyelles, A., Thompson, K., \& Howard, W. (2016). "Comfort" as a critical success factor in blended learning courses. Online Learning Journal, 20(3), 140-158. https://doi.org/10.24059/olj.v20i3.978

Garrison, D. R. (1997). Self-directed learning: Toward a comprehensive model. Adult Education Quarterly, 48(1), 18-33. https://doi.org/10.1177/074171369704800103

Haworth, R. (2016). Personal learning environments: A solution for self-directed learners. TechTrends, 60(4), 359-364.

Holt, D. T., Armenakis, A. A., Harris, S. G., \& Feild, H. S. (2007). Toward a comprehensive definition of readiness for change: A review of research and instrumentation. Research in Organizational Change and Development, 16(06), 289-336.

Hung, M. L., Chou, C., Chen, C. H., \& Own, Z. Y. (2010). Learner readiness for online learning: Scale development and student perceptions. Computers and Education, 55(3), 1080-1090. https://doi.org/10.1016/j.compedu.2010.05.004

Kennedy, D. M., \& Fox, B. (2013). ' Digital natives ': An Asian perspective for using learning technologies. International Journal of Education and Development Using Information and Communication Technology, 9(1), 64-79.

Kim, R., Olfman, L., Ryan, T., \& Eryilmaz, E. (2014). Leveraging a personalized system to improve self-directed learning in online educational environments. Computers and Education, 70, 150-160. https://doi.org/10.1016/j.compedu.2013.08.006

Knowles, M. S. (1975). Self-directed learning: A guide for learners and teachers. Cambridge Adult Education.

Lasfeto, D. B., \& Ulfa, S. (2020). The relationship between self-directed learning and students' social interaction in the online learning environment. Journal of E-Learning and Knowledge Society, 16(2), 34-41. https://doi.org/10.20368/1971-8829/1135078 
Le, T. T. M. (2021). A Case Study of Students' Views on Effective Online Learning. AsiaCALL Online Journal, 12(5), 24-33. Retrieved from https://www.asiacall.info/acoj/index.php/journal/article/view/73

Lee, C., Seeshing, A., \& Ip, T. (2017). University English language learners ' readiness to use computer technology for self-directed learning. System. https://doi.org/10.1016/j.system.2017.05.001

Maheshwari, G. (2021). Factors affecting students' intentions to undertake online learning: an empirical study in Vietnam. Education and Information Technologies. https://doi.org/10.1007/s10639-021-10465-8

Martin, F., Stamper, B., \& Flowers, C. (2020). Examining student perception of readiness for online learning: Importance and confidence. Online Learning Journal, 24(2), 38-58.

McVay, M. (2004). Learning Online: A guide to success in the virtual classroom. New York and London: Routledge.

Muliyah, P., Aminatun, D., Nasution, S. S., \& Hastomo, T. (2020). Exploring learners' autonomy in online language-learning in Stai Sufyan Tsauri Majenang. Getsempena English Education Journal, 7(2), 382-394. https://doi.org/10.46244/geej.v7i2.1164

Muthuprasad, T., Aiswarya, S., Aditya, K. S., \& Jha, G. K. (2021). Students' perception and preference for online education in India during COVID -19 pandemic. Social Sciences \& Humanities Open, 3(1), 100101. https://doi.org/10.1016/j.ssaho.2020.100101

Naji, K. K., Du, X., Tarlochan, F., Ebead, U., Hasan, M. A., \& Al-Ali, A. K. (2020). Engineering students' readiness to transition to emergency online learning in response to COVID-19: Case of Qatar. Eurasia Journal of Mathematics, Science and Technology Education, 16(10). https://doi.org/10.29333/EJMSTE/8474

Pillay, H., Irving, K., \& McCrindle, A. (2006). Developing a diagnostic tool for assessing tertiary students' readiness for online learning. Learning Technology, 2(1), 92-104.

Prihastiwi, W. J., Prastuti, E., \& Eva, N. (2021). E-Learning readiness and learning engagement during the Covid-19 pandemic. KnE Social Sciences, 3, 244-253. https://doi.org/10.18502/kss.v4i15.8212

Rivera, J. H. (2018). Online learner readiness: Strategies for success. Kappa Delta Pi Record, (54), 52-55.

Singh, V., \& Thurman, A. (2019). How many ways can we define online learning? A systematic literature review of definitions of online learning (1988-2018). American Journal of Distance Education, 33(4), 289-306. https://doi.org/10.1080/08923647.2019.1663082

Smith, P. J. (2005). Learning preferences and readiness for online learning. Educational Psychology, 25(1), 3-12. https://doi.org/10.1080/0144341042000294868 
Smith, P. J., Murphy, K. L., \& Mahoney, S. E. (2003). Towards identifying factors underlying readiness for online learning: An exploratory study. Distance Education, 24(1), 57-67. https://doi.org/10.1080/01587910303043

Tekkol, I. A., \& Demirel, M. (2018). An investigation of self-directed learning skills of undergraduate students. Frontiers in Psychology, 9, 1-14. https://doi.org/10.3389/fpsyg.2018.02324

Tran, Q. H., \& Nguyen, T. M. (2021). Determinants in Student Satisfaction with Online Learning: A Survey Study of Second-Year Students at Private Universities in HCMC. International Journal of TESOL \& Education, 2(1), 63-80. https://doi.org/10.54855/ijte22215

Warden, C. A., Yi-Shun, W., Stanworth, J. O., \& Chen, J. F. (2020). Millennials' technology readiness and self-efficacy in online classes. Innovations in Education and Teaching International, 00(00), 1-11. https://doi.org/10.1080/14703297.2020.1798269

Warner, D., Christie, G., \& Choy, S. (1988). The readiness of VET clients for flexible delivery, including online learning.

Wei, H. C., \& Chou, C. (2020). Online learning performance and satisfaction: do perceptions and readiness matter? Distance Education, 41(1), 48-69. https://doi.org/10.1080/01587919.2020.1724768

\section{Biodata}

Vy Luu Thi Mai is currently a lecturer at Ho Chi Minh City University of Economics and Finance in Vietnam. She got her PhD in English Language Studies at Suranaree University of Technology in Thailand. She has been teaching English for more than 10 years. She has presented in many international conferences (Thailand, China, Vietnam). Her research interests include theories in language learning and teaching, listening comprehension, pronunciation, prosody, CALL. 